\title{
La frontera México-Estados Unidos: mexicanización e internacionalización
}

\author{
Jean Revel Mouroz \\ Institut des Hautesudes de l'Amerique Latine \\ Université de París III-Sorbonne Nouvelle
}

\section{Resumen}

La presente investigación nos presenta una frontera de contacto directo que involucra a una superpotencia y a un país en vías de desarrollo. La frontera México-Estados Unidos es, en definitiva, una frontera antecedente porque su poblamiento es posterior a su delimitación jurídica. A lo largo de la línea fronteriza, la ósmosis económica de las ciudades en ambos países descansa, de manera general, en una interpenetración cultural. Si esta frontera es tan permeable con respecto a los productos y los hombres, es porque la línea de demarcación internacional no separa poblaciones realmente distintas a nivel regional. En base a los hechos aquí presentados, podemos deducir que comienza a estructurarse la cooperación deseada por las autoridades norteamericanas con respecto a un mercado común energético entre los Estados Unidos-Canadá-México.

Palabras clave: frontera permeable, ósmosis fronteriza, crecimiento demográfico, maquiladoras, delimitación jurídica.

\begin{abstract}
This research presents a direct contact border which involves a superpower country and a developing country. The Mexico-United States border is a formerly historical border because it was first peopled before a juridical delimitation was established. Along the border line, the economical osmosis of the cities from both countries usually lays on a cultural interpenetration. If this border is so permeable for products and people, it is due to international border line does not separate groups of people that are really different at a regional level. Based on the facts herein presented, it may be deducted that it is starting to structure the cooperation that American authorities thrive for regarding a common energetic market among the United States, Canada, and Mexico.
\end{abstract}

Keywords: permeable border, border osmosis, demographic growth, maquila industry, juridical delimitation. 


\title{
LA FRONTERA MEXICO-ES'TADOS UNIDOS: MEXICANIZACION E INTERNACIONALIZACION *
}

\author{
Por \\ Jean Revel-Mouroz \\ Maitre de Reserche an C.N.R.S. \\ Responsable del Equipo de Investigación sobre la Organización \\ Territorial en América Latina. Institut des Hautes Etudes de \\ l'Amerique Latine, Université de París III -Sorbonne Nouvelle.
}

\section{INTRODUCCION}

Frontera de contacto directo entre una superpotencia y un país en vías de desarrollo, la de México-Estacios Unidas $(3,125 \mathrm{~km}$ y 4.5 millones de personas residiendo en los condados y municipios limítrofes) es, en definitiva, una frontera antecedente porque su poblamiento es posterior a su delimitación jurídica.

Frontera viva durante tres siglos y medio, ella registra la relación de fuerzas desiguales que en el pasado llevaron a un conflicto abierto entre el México independiente y el nacimiento como potencia de los Estados Uniàos. Apoyándose en los cursos de lcs ríos Bravo y Colorado, así como sobre la geometría de paralelas; no es únicamente una frontera natural, por cortar indistintamente unidades físicas reales como son las sierras, las mesetas desérticas y grandes deltas.

No es posiole tampoco, hablar de frontera cultural o lingüística entre dominio mexicano y "anglo", en el momento que el crecimiento de las migraciones mexicanas recolonizan el suroeste perdido.

Frontera reveladora del subdesarrcllo, ella acentúa las características propias a toda economía dependiente, cuya supervivencia es posible únicamente por su integración a la moderna división internacional del trabajo.

\section{LA FRONTERA VIVIENTE.}

\section{La expansión colonial.}

Durante tres siglos (1521-1821), la apertura del Norte mexicano -las "provincias internas" coloniales- es el producto de una frontera de guerra

\footnotetext{
- El presente texto fue preparado para las jornadas de estudio sobre "El problema de las fronteras". Evento organizado el 20 y 21 de marzo de 1981 por el Laboratorio Conocimiento del Tercer Mundo, de la Universidad de París VII en colaboración de la Revista PLURIEL-DEBAT. La traducción al español fue hecha por Arturo Ranfla González.
} 
contra los indios, primero chichimecas, después los comanches y los apaches. Esta frontera pionera progresa en los desiertos o en el milagro de las ciudades doradas de Cibola; después, los descubrimientos de las minas de plata de $\mathrm{Za}^{-}$ catecas y Chihuahua conducen a los españoles hasta el corazón de lo que son actualmente los Estados Unidos.

La frontera 1 es, en primera instancia, una frontera en el sentido norteamericano. Minas reales, islotes agrícolas y grandes dominios ganaderos para aprovisionar las ciudades mineras, guarniciones de señalamiento del Camino Real de México a Santa Fe desde fines del siglo XVI. Al Oeste, dos cadenas de misiones ancladas en Baja California y Sinaloa para unir tardíamente San Francisco y Tucson (1776); al Este, la penetración de Texas por los misioneros y sobre el bajo Río Bravo (1749).

Pero el poblamiento permanece precario: los indios huyen de las persecusiones y acosan a los colonos; fuera će esos cuatro grandes ejes Norte-Sur, lo demás es el vacío.

A finales del siglo XVIII, si la frontera jurídica de las posesiones españolas alcanza al paralelo $42^{\circ}$ de latitud y engloba Lousiana y Florida, la frontera real delimitando el espacio mexicano efectivamente controlado sigue una traza vecina de la frontera actual entre México y Estados Unidos; sobre los centros de avanzada de San Antonio y de Santa $\mathrm{Fe}$, la frontera está físicamente marcada por el cordón de presidios, fuertes y guarniciones sistemáticamente implantadas entre 1772 y 1800 para evitar las incursiones indias sobre los territorios norteños integrados a la explotación.

\section{La fase de comprensión.}

Las audaces implantaciones españolas en el Missisipi y California responden a la voluntad de frenar las ambiciones de franceses, ingleses (después americanos) y rusos, consolidạ́ndose hasta el cambio radical que resulta del surgimiento de un nuevo vecino, los Estados Unidos, que conduce al derrumbe del poder colonial.

La venta de Lousiana por Bonaparte en 1803 dota de una frontera común a los Estados Unidos y el virreinato de la Nueva España. Esta frontera se había fijado por el paralelo 420 de latitud y por las riberas de Sabinas y el Río Rojo, en el tratado de delimitación firmado en 1819 entre España y Estados Unidos, límites que fueron confirmados después de la Independencia mexicana por un nuevo tratado entre México y Estados Unidos (1827).

1 En el texto original (N. de T.) 


\section{FIGURA 1. La frontera viviente.}

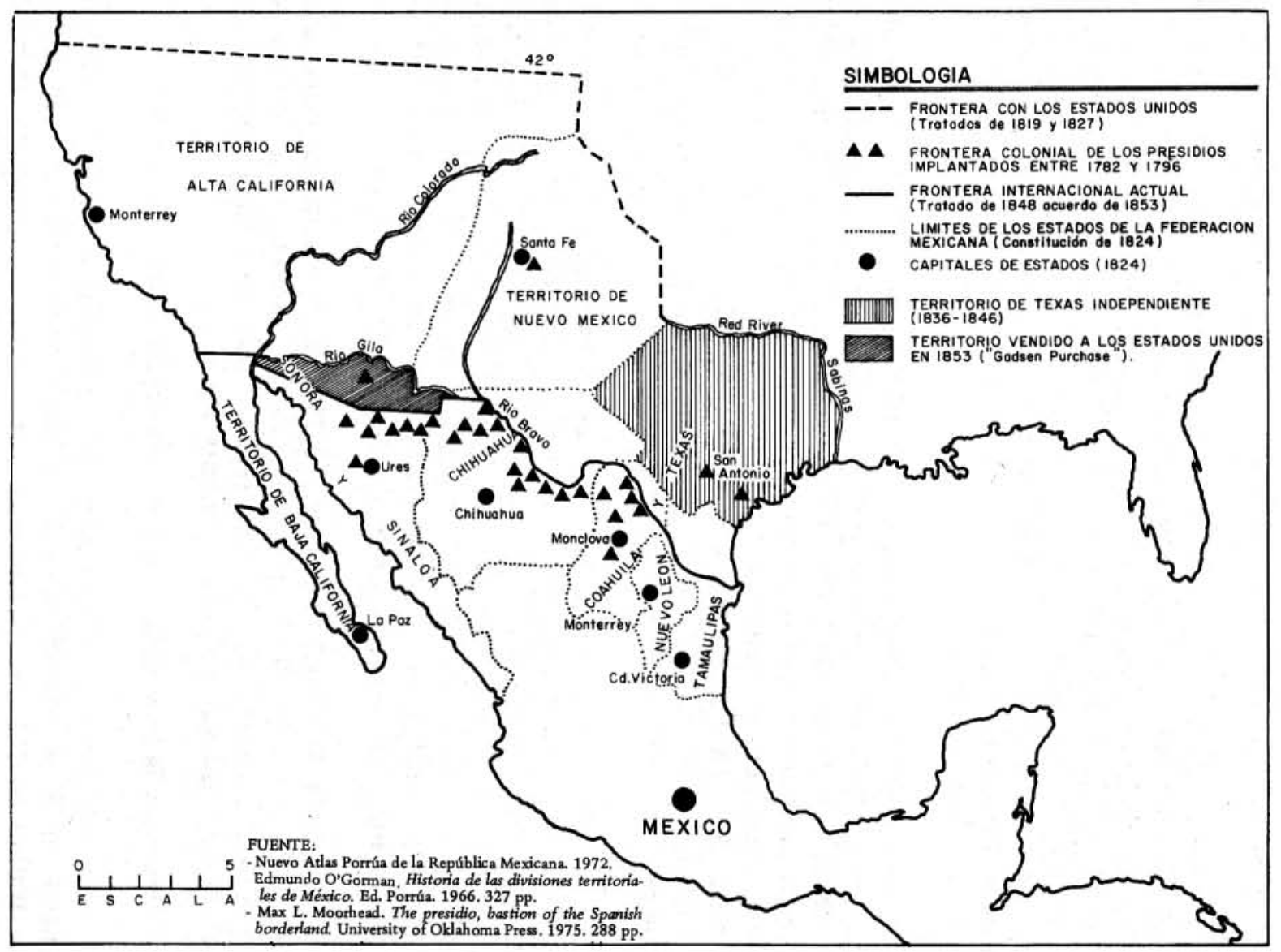


A pesar de los acuerdos de demarcación, la frontera continuaba "viviente". En efecto: "La frontiere est seulement le resultat d'un equilibre entre les forces vitales de deux peuples. Elle n'a jamais eu une valeur absolue" 2

Como resultado de la Guerra de Independencia y posteriormente de las guerras civiles, México se debilita, desorganizándose la economía minera y desguarneciéndose los presidios. Con esto se abre la puerta a los indios y se provoca un reflejo de las implantaciones del Norte, con lo cual la "frontera" de poblamiento por parte de los colonos anglosajones llega hasta el territorio mexicano. Frente al poder central mexicano, desgarrado entre facciones, se afirma el deseo norteamericano de tomar el control de un espacio necesario para la realización del destino manifiesto.

En un primer momento la presión es indirecta. De 1831 a 1834 un movimiento de rebelión contra el gobierno central aparece en Texas, que forma parte de uno de los estados de la Federación Mexicana. Esta rebelión, encabezada por colonos anglos así como por regionalistas mexicanos, conduce al pronunciamiento de marzo de 1835 , al grito de: "Libertad, Constitución y Federación". La victoria de los texanos sobre el caudillo Santa Ana en 1936 da la independencia a Texas, la cual se reconoce por los Estados Unidos y ciertos países europeos, perc no por México.

En 1845, a solicitud de las autoridades texanas, el Senado de los Estados Unidos pronuncia la anexión de Texas; esta medida, junto con una serie de provocaciones militares, conducen a una guerra entre los Estados Unidos y México, a iniciativa del presidente norteamericano. Con sus ejércitos derrotados y su capital ocupada, México debe ceder en 1848, con el Tratado de Guadalupe-Hidalgo, un territorio correspondiente a los Estados de California, Nevada, Utah, Arizona, Colorado, Nuevo México y Texas.

En 1853, México debe vender $110,000 \mathrm{~km}^{2}$ (compra Gadsen) lo que cede a los Estados Unidos la traza meridional en Arizona de la comunicación terrestre (posteriormente ferroviaria) Texas-California, en el momento que la ruta hacia el oro va a poblar este último estado.

La frontera y la formación de un espacio dependiente, 1853-1910.

Durante este perfodo la integridad territorial mexicana es varias veces puesta en duda: expediciones de "filibusteros" norteamericanos (como la de Walker en 1853 en el Noroeste), de aventureros franceses viniendo de California a conquistar Sonora (Raousset en 1855-54), e inclusive regionalismo centrífugo de grandes caciques políticos como Vidaurri en el Noreste.

2 ANGEL J., Geographie des Frontieres, 1938. 
Inclusive un ciclo "texano" parece desarrollarse con la "invasión socialista" de Baja California, dirigida por los hermanos Flores Magón con el apoyo de los sindicatos norteamericanos. Asimismo, la infiltración de aventureros buscando aprovecharse del vacío político creado localmente por la Revolución Mexicana. Más allá de todas estas iniciativas individuales, el interés del gobierno norteamericano en estos territorios está subyacente: es así, que el presidente Bucharan solicita al Congreso, en 1858, que autorice la compra de Baja California, Sonora y Chihuahua, que son prolongaciones naturales de montañas y mesetas del Sudoeste. La Guerra de Secesión desvía las tentaciones norteamericanas de anexión, mientras que la intervención francesa (1861-1867) los obliga a convertirse en protectores del régimen liberal y de la soberanía de México.

A finales del siglo XIX, el objetivo no es continuar la expansión territorial hacia el Sur, pues se trata más bien de explotar los recursos mexicanos. La frontera pierde su función militar (con excepción de las tribus nómadas) hasta la Revolución Mexicana.

Para México, la frontera tiene una función principalmente económica: los ingresos del Estado provienen, en esa época, esencialmente de los impuestos al comercio exterior; las aduanas fronterizas (como Ciudad Juárez y Nuevo Laredo) adquieren una importancia estratégica en el momento que las comunicaciones ferroviarias Norte-Sur entre México y Estados Unidos (cuyas obras se realizaron entre 1880-1980) multiplican sus intercambios. Durante la Revolución Mexicana los puestos fronterizos existentes fueron disputados por los ejércitos, ya que cada facción buscaba asegurar el control de ingresos aduanales y el acceso al aprovisionamiento del armamento proveniente de los Estados Unidos.

Para los pioneros, empresarios y capitalistas norteamericanos, la frontera estuvo abierta durante el régimen del general Porfirio Díaz (1876-1911). Las compañías ferroviarias abren camino a las sociedadesmineras, a los barones del ganado, a las compañías de irrigación que penetran todo el Norte mexicano y lo transforman en un espacio económico dependiente. Es el expansionismo propio a la "frontera" del Oeste americano que encuentra en México millones de hectáreas a colonizar gracias a las leyes mexicanas que favorecían a la inversión extranjera. Verdaderos enclaves fronterizos se forman en esta época: mineros (Cananea), agrícolas (bajo Colorado), pastorales (Chihuahua), directamente ligados a los centros metropolitanos de California, Arizona o de Texas.

Gracias a estas inversiones masivas y la corriente comercial que muestra notable crecimiento (el comercio entre México y los Estados Unidos pasa de 15 a 117 millones de dólares entre 1880 y 1910), los puntos de pasaje fron- 
terizo se transforman en pequeñas ciudades; con Matamoros, Nuevo Laredo; Piedras Negras, Ciudad Juárez y Mexicali, aparecen las bases para un crecimiento urbano fronterizo.

\section{LA OSMOSIS FRONTERIZA: DEL CONFLICTO AL INTERCAMBIO DESIGUAL}

La revolución mexicana de 1910-1917 y la nueva Constitución instauran un Estado profundamente nacionalista cuyo objetivo central es destruir los enclaves extranjeros.

\section{A la reconquista del territorio.}

La Constitución de 1917 elimina la propiedad extranjera del suelo en una banda de $100 \mathrm{~km}$ a lo largo de la frontera, y de $50 \mathrm{~km}$ a lo largo de las costas. A esto se agrega la Ley de Reforma Agraria del régimen cardenista (1934-1940) aplicada a los latifundios intensivos extranjeros. Los intereses norteamericanos son de esta manera eliminados de las zonas de irrigación del Noroeste, mientras que los dominios de las compañías mineras y ferroviarias son repartidos; sólo los grandes dominios destinados principalmente a la ganadería resisten más tiempo a la mexicanización (la que no es totalmente efectiva hasta los años setenta), al abrígo de cláusulas protectoras de la producción animal.

El Estado mexicano interviene directamente a lo largo de la frontera creando grandes distritos de irrigación (Colorado, bajo Río Bravo) administrados por la Secretaría de Recursos Hidráulicos. La agricultura de irrigación, en base al cultivo de algodón, se convierte en motor de poblamiento fronterizo y base del desarrollo de capitales agrícolas como Mexicali y Matamoros.

Con todas estas circunstancias, la reconquista del territorio no implica el de la economía en su conjunto: las compañías americanas continúan financiando y comercializando la producción algodonera y la extracción y exportación de los minerales no ferrosos (cobre, zinc, etc.).

La economía urbana fronteriza: una ósmosis con los Estados Unidos.

Alimentados por los flujos de refugiados de las luchas revolucionarias, religiosas (guerra de los cristeros, 1926-1929), por el de los nuevos colonizadores agrícolas y por el de los migrantes de trabajo (deteniéndose en marcha hacia los Estados Unidos o expulsados de este país por los efectos de la cri- 
sis de 1929), las poblaciones urbanas fronterizas instauran un sistema económico local para responder a una demanda original de los consumidores norteamericanos.

Las ciudades fronterizas se convierten en exutorio para esos "turistas del vicio" cuando la prohibición se desarrollaba en Estados Unidos y se promulgaban leyes contra la prostitución y juegos de azar en Texas y California. En los años veinte, con el sostén "tecnológico" y financiero de la delincuencia norteamericana, las ciudades mexicanas se equipan en bares, prostíbulos e hipódromos, con lo que adquieren su reputación del "poso del mundo3". La frontera se convierte en la línea de demarcación entre el reino del puritanismo y aquel de los placeres venales.

La Segunda Guerra Mundial favorece la expansión de estas actividades en la región al concentrar los Estados Unidos fuertes volúmenes de poblaciones militares en sus bases fronterizas (San Diego, El Paso, Nuevo Laredo), favoreciendo al mismo tiempo el contrabando de productos racionados en este país.

En este conjunto de actividades "marginales", las burguesías locales fundan su éxito económico, que se consolidará posteriormente en las actividades de importación-exportación, la banca, la industria y los bienes inmuebles.

A partir de 1942, con el inicio de los programas de braceros (migrantes temporales mexicanos reclutados para sustituir a los trabajadores norteamericanos movilizados), la función de etapa y de base para los migrantes mexicanos hacia los Estados Unidos incrementa el dinamismo de las ciudades de frontera. A partir de este momento es posible hablar de una frontera de urbanización, polarizando las migraciones del norte y del centro-oeste del país, que la coloca inmediatamente después de la ciudad de México por lo que toca a los efectivos captados. Las ciudades de la frontera triplican su población entre 1940 y 1950 y la duplican en el decenio siguiente.

La economía local se especializa en función de las ventajas comparativas resultantes del bajo costo de la mano de obra y de la tolerancia oficial con relación a las actividades marginales. Sin embargo, a la migración de los consumidores norteamericanos responde un flujo inverso de visitantes mexicanos en las ciudades-fronterizas (gemelas) del lado americano. En efecto, aprovechando las economías de escala que resultan del tamaño de su mercado interno, las grandes sociedades americanas han convertido las ciudades fronterizas de Texas, Arizona y California en polos comerciales, drenando la 3 DEMARIS O., Paso del Mundo; inside of the Mexican-American border, from Tijuana to Matamoros. Little
Brown Ed, 1970. 
CUADRO 1. Crecimiento de las ciudades fronterizas (miles).

\begin{tabular}{|lrrrrrrrr|}
\hline & 1910 & 1921 & 1930 & 1940 & 1950 & 1960 & 1970 & 1979 \\
\hline Tijuana & 0.7 & 1.0 & 8.4 & 16.5 & 60.0 & 152.0 & 327.0 & 566.0 \\
Mexicali & 0.4 & 6.8 & 14.8 & 18.8 & 65.0 & 175.0 & 267.0 & 349.0 \\
Ciudad Juárez & 10.6 & 19.5 & 39.7 & 48.9 & 123.0 & 262.0 & 436.0 & 625.0 \\
Nuevo Laredo & 8.1 & 15.0 & 21.6 & 28.9 & 58.0 & 93.0 & 149.0 & 224.0 \\
Reynosa & 1.5 & 2.1 & 4.8 & 9.4 & 34.0 & 74.0 & 137.0 & 231.0 \\
Matamoros & 7.4 & 9.2 & 9.7 & 15.7 & 46.0 & 92.0 & 138.0 & 193.0 \\
\hline
\end{tabular}

FUENTE: III, IV $b$ V, VI, VII, VIII y IX Censos Generales de Población. 1979, proyección S.I.C.

clientela mexicana (en una zona de 1000 a $1500 \mathrm{kms}$ al interior) consumidora de textiles, productos industrializados y aparatos para el hogar. La división del trabajo que se observa entre estas ciudades gemelas de la frontera refleja, hasta la caricatura, las relaciones asimétricas de las economías americana y mexicana.

El doble flujo de consumidores (más de 150 millones de cruces por año) se traduce en un volumen de transacciones fronterizas que alcanzan respectivamente 298 millones de dólares (lado mexicano) y 230 millones (lado americano) en 1979. Esta intensidad de intercambios se explica (aparte de las ventajas comparativas entre los costos de productos y de servicios) por:

- La penetración del modelo de consumo de masa norteamericano en la población mexicana, particularmente en la frontera, en que una red de medios (estaciones de T.V. y radios emitiendo en español campañas de prensa y publicidad) ejerce una presión publicitaria constante;

- La existencia, en los Estados Unidos, de una minoría de origen mexicano que permanece fiel a su cultura de origen y cruza la frontera para encontrarla a través del consumo de servicios y productos mexicanos.

Esto nos permite verificar que la ósmosis económica de las ciudades fronterizas descansa, de manera general, en una interpenetración cultural. 
Si esta frontera es tan permeable con respecto a los productos y los hombres, es porque la línea de demarcación internacional no separa poblaciones realmente distintas a nivel regional.

\section{LA FRONTERA CULTURAL ABOLIDA: LA MEXICANIZACION DEMOGRAFICA.}

\section{La reconquista silenciosa}

Cuando México cede, en 1848, una parte de su territorio a Estados Unidos, la población "mexicana" se elevará a 60,000 personas en Nuevo México, 8 a 10,000 en California, 5 a 6,000 en Texas y un millar en Arizona; es decir, entre 75,000 y 80,000 en total. Un siglo más tarde la población de origen mexicano censada en los estados del Suroeste alcanzaba en 1950 los 2.4 millones de personas. En un tiempo no muy lejano, una reconquista demográfica debe convertir a la población "méxico-americana" en la segunda minoría étnica-cultural de los Estados Unidos.

Esta mexicanización se desarrolla a lo largo de la frontera en las grandes ciudades que captan las corrientes migratorias. Si al interior de California, la ciudad de Los Angeles tiene oficialmente una población de 1,050,000 mexicanos en 1970, en la misma fecha la población "mexicana" es mayoritaria en dieciseis de los veinticinco condados fronterizos. Una ciudad como El Paso vio pasar la proporción de población de origen mexicano de 20 \% en 1890 a 57 \%o en 19704 .

Para el período 1950-1970, los estados fronterizos doblaron su población "mexicana". Este dinamismo obedece a dos factores: por un lado a la mayor fertilidad de la población de origen mexicano en relación a la población de origen anglo; por otra parte, y sobre todo, a una migración de masa legal e ilegal, que ninún gobierno americano ha podido detener.

\section{La migración mexicana y los problemas fronterizos.}

A principios de este siglo la migración mexicana se estructuró hacia las áreas rurales y las ciudades del Sudoeste; a través de la constitución de verdaderos canales migratorios se drenaron anualmente varios millones de personas: durante 1978-1979, de 950,000 a un millón de trabajadores en situación ilegal fueron expulsados de los Estados Unidos, estimándose que por cada indocumentado detenido, tres no son detectados.

\footnotetext{
${ }^{4}$ MARTINEZ, O.J., Border boom town: Ciudad Juárez since 1848. University of Texas, Austin, 1978.
} 
Después de 1964 , bajo la presión de s $\bullet$ dicatos, el gobierno americano detuvo la inmigración de braceros legales al mismo tiempo que aplicaba cuotas más rigurosas a la inmigración mexicana propiamente dicha (cuota de 20,000 en lugar de 40,000 migrantes por año).

En 1975 una estimación realizada porr cuenta del Servicio de Inmigración y Naturalización avanzaba la cifra de 5.2 millones de mexicanos en situación ilegal en Estados Unidos. Evocando la dimensión de esta migración, William Colby, antiguo director de la C.I.A., declaraba: "Veinte millones (de mexicanos) vendrán a vivir aquí (hasta el año 2000). . . El más grande pcligro de violencia en el mundo viene de la diferencia entre ricos y pobres, nosotros contra ellos. . (es) una invasión silenciosa que puede ser más peligrosa para los Estados Unidos que la misma Unión Soviética 5".

Para reducir ese peligro, que geográficamente concentrado alimenta la inquietud con respecto a la minoría de chicanos, la administración Carter reforzó la vigilancia de la frontera por medio de la Border Patrol, multiplicando arrestos y expulsiones, imaginando una "barrera electrónica" y construyendo barreras en las ciudades fronterizas. Se trató de detectar, desde la entrada a los Estados Unidos, a todo migrante ilegal, explotado por toda una fauna de intermediarios y que provoca derrama monetaria a cada paso fraudulento.

Esta política malthusiana no puede sin embargo llegar a sus últimas consecuencias, porque después de 1976 el gobierno americano debe tener en cuenta el peso político creciente de un país convertido en gran exportador de petróleo, que favorece su margen de negociación con su vecino del Norte. El barril de petróleo viene al rescate del indocumentado. Por otra parte, ¿cómo convertir a la frontera en impermeable con respecto a los migrantes, cuando la economía de las ciudades fronterizas descansa precisamente en la movilidad de los consumidores? ; ¿cómo distinguir unos de otros?

Actualmente, la política norteamericana se orienta hacia una regularización de los mexicanos residiendo ilegalmente en los Estados Unidos además de un contingente anual de trabajadores temporales.

Después de un primer programa el "Plan Carter" fue rechazado por el Congreso en 1977; recientemente, el presidente Reagan elaboró un nuevo proyecto; según las declaraciones del abogado general, M.W. French-Smith, en el mes de junio de 1981 el proyecto descansaba en las propuestas siguientes:

5 Declaración en Los Angeles Times, junio 6, 1978. 
- Un estatuto legal será acordado a todo residente clandestino que se encuentre en los Estados Unidos antes del primero de enero de 1980 (con la obligación de cubrir un largo período probatorio, con severas restricciones con respecto a la asistencia social y a la instalación de miembros de su familia).

- Una medida específica para los mexicanos prevé la posibilidad de que un cierto número obtenga el estatuto de trabajador "temporal", quizá 50,000 por año en una primera fase.

Sin embargo, la duda persiste con respecto a este nuevo programa de braceros sobre su capacidad de eliminar la migración clandestina cuando el problema clave permanece sin solución: ¿cuáles son las razones que producen la migración?

\section{LA ZONA FRONTERIZA, ZONA PRIVILEGIADA EN LA NUEVA DISTRIBUCION INTERNACIONAL DE LA INDUSTRIA}

La idea de luchar contra el fenómeno migratorio tiene su origen en la creación de empleos industriales, y ha progresado muy particularmente en los estados del Norte. A principios de 1979, M. Mc. Namara, presidente del Banco Mundial, explicaba que los Estados Unidos no tenían más que dos posibilidades de acción frente al problema de los indocumentados: abrir su frontera a los productos mexicanos o bien a la mano de obra mexicana; agregaba que la sola medida que podía detener la emigración era la industrialización de México. Crear empleos y exportar hacia los Estados Unidos, constituyen dos de los objetivos públicamente declarados del gobierno mexicano actual.

En la misma frontera, un instrumento con esas finalidades existe después de 1965: el Programa de Industrialización de la Frontera Norte, que se articuló gracias a la delocalización de la industria internacional con base en las industrias de fuerte contenido de mano de obra. Este programa, creado para reducir el desempleo en las ciudades fronterizas el cual alcanzé niveles críticos por el reflujo de braceros, buscó atraer empresas industriales que se beneficiaban en tres aspectcs: 1) por la utilización de una mano de obra abundante cuyo costo salarial era de 3 a 4 veces inferior al costo salarial de una localización en los Estados Unidos; 2) por la legislación aduanal norteamericana que no preveía impuestos a la importación -en el caso de los productos, incorporando elementos de origen americano- sino sólo sobre el valor agregado al extranjero; y 3) por la legislación ad boc mexicana, que exenta al ensamble o maquila de los derechos de importación y de exportación (equipos, materias primas. ..) a condición que la totalidad de la producción sea destinada a la exportación. 
CUADRO 2. México-Estados Unidos / masas y dinámica

\begin{tabular}{|c|c|c|c|}
\hline & ESTADOS UNIDOS & MEXICO & $1 / 2$ \\
\hline Superficie (km 2) & 9363000 & 1973000 & 4.75 \\
\hline Población (1980) & 227 millones & 67 millones & 3.39 \\
\hline Crecimiento natural & $6.5 / 1000$ & $33.4 / 1000$ & 0.19 \\
\hline P. I. B. (1977) & $\begin{array}{l}1.879 \text { billones } \\
\text { de dólares }\end{array}$ & $\begin{array}{l}74 \text { mil millones } \\
\text { de dólares }\end{array}$ & 25.39 \\
\hline $\begin{array}{l}\text { P. I. B. variación anual } \\
1979\end{array}$ & $+2.4 \%$ & $+8.0 \%$ & 0.3 \\
\hline 1980 & $-0.1 \%$ & $+7.4 \%$ & 0.3 \\
\hline
\end{tabular}

FUENTES: Anuario Estad ístico 1979.

Banco de México. Informe anual 1980.

O.C.D.E. Principaux Indicateurs Economiques.

CUADRO 3. La frontera México-Estados Unidos: su peso en la economía mexicana.

\begin{tabular}{|c|c|c|c|c|}
\hline & 1976 & & 1979 & \\
\hline GASTO CORRIENTE & $10^{6}$ & $\%$ & $10^{6}$ & $\%$ \\
\hline Ingresos. . . . . . . . . & 7231,2 & 100 & 16187,9 & 100 \\
\hline Exportaciones (mercancias) & 3315,8 & 45,9 & 8798,2 & 54,4 \\
\hline Turismo & 835,6 & 11,6 & 1443,3 & 8,9 \\
\hline a. Transacciones fronterizas & 1609,7 & 22,3 & 2981,8 & 18,4 \\
\hline b. Maquiladoras (valor agregado) & 520,1 & 7,2 & 637,6 & 3,9 \\
\hline $\mathrm{a}+\mathrm{b}=\mathrm{a}$. Actividades de la frontera & 2129,8 & 29,5 & 3619,4 & 22,4 \\
\hline OTROS INGRESOS & 950,0 & 13,1 & 2326,9 & 14,4 \\
\hline Egresos $\ldots \ldots \ldots \ldots \ldots$ & 10275,6 & 100 & 21052,4 & 100 \\
\hline Importaciones (mercancias) & 6029,6 & $\overline{58,7}$ & 12613,0 & $\overline{59,9}$ \\
\hline Turismo & 382,9 & 3,7 & 713,6 & 3,4 \\
\hline Transacciones fronterizas & 1051,5 & 10,2 & 2302,1 & 10,9 \\
\hline OTROS & 2811,6 & $\overline{27,4}$ & $\overline{5423,7}$ & 25,8 \\
\hline Saldo $\ldots \ldots \ldots \ldots \ldots$ & $-3044,4$ & & $-4864,5$ & \\
\hline Mercancf́as & $-2713,8$ & & $-3814,8$ & \\
\hline Turismo & $+452,7$ & & $+729,7$ & \\
\hline Actividades de la frontera & $+1078,3$ & & $+1317,3$ & \\
\hline OTROS & $-1861,6$ & & $-3096,8$ & \\
\hline
\end{tabular}

FUENTE: Banco de México. Informe Anual 1977 y 1979. 
Jean Revel Mouroz

CUADRO 4. Estados Unidos: la mexicanización de la frontera. Población de origen mexicano en los estados y condados fronterizos.

\begin{tabular}{|c|c|c|c|c|c|c|}
\hline \multirow{2}{*}{$\begin{array}{l}\text { ESTADOS Y CONDADOS } \\
\text { CALIFORNIA }\end{array}$} & \multicolumn{2}{|c|}{$\begin{array}{c}1950 \\
\text { APELLIDO ESPANOL } \\
\text { No. o/o de la po- } \\
\text { blación }\end{array}$} & \multicolumn{2}{|c|}{$\begin{array}{c}1960 \\
\text { APELLIDO ESPANOL } \\
\text { No. \% dela po- } \\
\text { blación }\end{array}$} & \multicolumn{2}{|c|}{$\begin{array}{c}1970 \\
\text { APELLIDO ESPAÑOL }\end{array}$} \\
\hline & 758400 & 7.2 & 1426500 & 9.1 & 2222200 & 11.2 \\
\hline San Diego & 29000 & 5.2 & 64800 & 6.3 & 173800 & 12.8 \\
\hline Imperial & 19000 & 30.2 & 23900 & 33.1 & 34300 & 46.0 \\
\hline ARIZONA & 128600 & 12.9 & 194400 & 14.9 & 246400 & 13.9 \\
\hline Yuma & 6400 & 22.6 & 9300 & 20.1 & 16200 & 26.7 \\
\hline Pima & 27300 & 19.3 & 44500 & 16.7 & 83000 & 23.6 \\
\hline Santa Cruz & 5300 & 56.6 & 6200 & 57.6 & 10800 & 77.3 \\
\hline Cochise & 10100 & 32.2 & 13800 & 25.5 & 20600 & 33.3 \\
\hline NUEVO MEXICO & 248600 & 36.5 & 269100 & 28.3 & 324200 & 31.9 \\
\hline Hidalgo & 2000 & 40.0 & - & - & 2800 & 57.7 \\
\hline Grant & 10100 & 46.7 & 8800 & 47.2 & - & - \\
\hline Luna & 3200 & 36.4 & 3400 & 34.4 & 5400 & 46.5 \\
\hline Dona Ana & 20900 & 52.8 & 25200 & 42.1 & 35400 & 50.8 \\
\hline TEXAS & 1027500 & 13.3 & 1417800 & 14.8 & 1663600 & 14.9 \\
\hline El Paso & 89500 & 45.9 & 137000 & 43.6 & 204400 & 56.9 \\
\hline Hudspeth & 2900 & 66.7 & - & - & 1400 & 60.9 \\
\hline Culberson & 700 & 39.4 & - & - & 1700 & 50.1 \\
\hline Jeff Davis & 1200 & 55.2 & - & - & 900 & 55.2 \\
\hline Presidio & 5100 & 69.8 & 2700 & 49.4 & 3600 & 75.3 \\
\hline Brewster & 3100 & 41.8 & 2700 & 42.6 & 3700 & 47.8 \\
\hline Terrel & 1600 & 51.7 & - & - & 800 & 41.6 \\
\hline Valverde & 10500 & 63.0 & 10800 & 44.2 & 15500 & 56.6 \\
\hline Kinney & 1400 & 53.7 & - & - & 1500 & 71.5 \\
\hline Maverick & 9000 & 73.6 & 11300 & 77.6 & 16300 & 90.3 \\
\hline Webb & 47600 & - 84.7 & 51800 & 79.9 & 62400 & 85.6 \\
\hline Zapata & 4100 & 94.1 & 3300 & 74.8 & 4000 & 91.5 \\
\hline Starr & 12500 & 89.3 & 15200 & 88.7 & 17300 & 97.9 \\
\hline Hidalgo & 112500 & 70.1 & 129100 & 71.4 & 143600 & 79.1 \\
\hline Cameron & 81100 & 64.8 & 97000 & 64.0 & 107000 & 76.2 \\
\hline CUATRO ESTADOS & 2163000 & 11.0 & 3307900 & 10.0 & 4456400 & 13.1 \\
\hline CONDADOS FRONTERIZOS & 516000 & 34.0 & 600800 & 27.8 & 966400 & 33.9 \\
\hline $\begin{array}{l}\text { CONDADOS FRONTERIZOS } \\
\text { ( }+ \text { de } 15,000 \text { habitantes } \\
\text { en } 1970 \text { ) }\end{array}$ & 437400 & 30.4 & 633700 & 27.6 & 929800 & 33.2 \\
\hline
\end{tabular}


CUADRO 5. La población de origen mexicano en los Estados Unidos. Una estimación

\begin{tabular}{|c|c|c|c|}
\hline & 1950 & 1960 & 1970 \\
\hline \multicolumn{4}{|l|}{ APELLIDO ESPAÑOL } \\
\hline Total del Suroeste & 2281710 & 3464999 & 4667975 \\
\hline California & 758400 & 1426538 & 2222185 \\
\hline Texas & 1027455 & 1417810 & 1663567 \\
\hline Arizona & 128580 & 194356 & 246390 \\
\hline Nuevo México & 248560 & 269122 & 324248 \\
\hline Colorado & 118715 & 157173 & 211585 \\
\hline \multicolumn{4}{|l|}{ ORIGEN MEXICANO } \\
\hline Total del Suroeste . . . . . . . & 2221710 & 3333602 & 4345796 \\
\hline Otros estados . . . . . . . . & $130000 *$ & $224934^{*}$ & 593801 \\
\hline TOTAL $\ldots \ldots \ldots \ldots$ & $2351710^{*}$ & $3558536^{*}$ & 4939597 \\
\hline $\begin{array}{l}\text { Estimación de la población } \\
\text { legal de origen mexicano no } \\
\text { censada } \ldots \ldots \ldots \ldots \ldots \ldots\end{array}$ & $200000^{*}$ & $400000^{*}$ & $800000^{*}$ \\
\hline $\begin{array}{l}\text { Estimación de la población } \\
\text { ilegal de origen mexicano no } \\
\text { censada } \ldots \ldots \ldots \ldots \ldots \ldots \ldots\end{array}$ & $600000 *$ & $1000000^{*}$ & $2000000^{*}$ \\
\hline $\begin{array}{l}\text { Estimación de los migrantes } \\
\text { fronterizos presentes en los } \\
\text { Estados Unidos. . . . . . . . }\end{array}$ & $400000^{*}$ & $200000 *$ & $600000^{*}$ \\
\hline $\begin{array}{l}\text { Estimación de la población } \\
\text { de origen mexicano presente } \\
\text { en los Estados Unidos. . . . . . }\end{array}$ & $3551710^{*}$ & $5158536^{*}$ & $8339597^{*}$ \\
\hline
\end{tabular}

FUENTE :Arthur F. Forwin. Quien Sabe? Mexican Migration Statistics. dan: Arthur F. Corwin editeur. Immigrants and Immigrants. Perspectives on Mexican Labor Migrations to the United States. Greenwood Press 1978. p. 124.

* = Estimaciones. 
Estas ventajas explican la corriente migratoria industrial (las "run away plants") Norte-Sur, inversa de la migración de trabajo Sur-Norte. El proceso ha afectado principalmente industrias como la electrónica, la confección, los juguetes, instrumentos de precisión y más recientemente las piezas de automóviles.

El número de maquiladoras pasó de 12 en 1967 a una centena en 1969 y a 620 en 1980 (de las cuales 537 estaban en la misma frontera). Estas industrias de montaje, empleando 122,000 personas en 1980, crearon en ciudades fronterizas de economía terciaria, un sector industrial generador de salarios regulares.

Independientemente de lo anterior, la cuestión del desempleo no se ha resuelto: el empleo creado por las maquiladoras es aproximadamente en un 90 \% femenino, y no toca prácticamente a los hombres subempleados, que continúan yendo a buscar un trabajo ilegal en los Estados Unidos. Así se desarrolla una nueva división internacional del trabajo, interna al núcleo familiar esta vez: esposa e hijas trabajan en las maquiladoras mientras que padre e hijos se incorporan al sector informal o se internan a los Estados Unidos.

Este fenómeno está muy desarrollado en ciudades como Ciudad Juárez $(38,000$ empleos), Matamoros $(16,000)$ o Nogales $(13,000)$, lugares en que se puede constatar el crecimiento de enclaves industriales que se convierten en motor de la economía local, pero motor sujeto a las violentas variaciones de la demanda del mercado americano.

\section{CONCLUSION}

La frontera mexicana, donde los problemas territoriales y de demarcación fueron resueltos (lo que constituye una excepción en América Latina) por el tratado de 1970, firmado por los presidentes Nixon y Díaz Ordaz, así coma los problemas ligados a la utilización de ríos y aguas internacionales por el Tratado de Aguas en 1944 y el Acuerdo de 1973 (sobre la salinización del Río Colorado), ve desvanecerse con estas medidas, toda fuente de conflicto con respecto a la frontera.

En oposición al aspecto formal, la manipulación de la barrera fronteriza entre las jurisdicciones de dos soberanías nacionales traduce la situación dependiente de México con relación a Estados Unidos, siendo este último el único a utilizar el cierre de la frontera (temporalmente a ciertos productos mexicanos, e inclusive a los migrantes) como medio de presión para modificar la política mexicana. 
CUADRO 6. Enclaves industriales de exportación: las maquiladoras.

\begin{tabular}{|c|c|c|c|c|c|c|c|}
\hline $\begin{array}{l}\text { MUNICIPIOS } \\
\text { FRONTERIZOS }\end{array}$ & & $\begin{array}{l}\text { de } \\
\text { resas } \\
\% \%\end{array}$ & $\begin{array}{l}\text { Persor } \\
\text { emple: }\end{array}$ & $\begin{array}{l}\text { ad } \\
\text { ado } \\
\% \\
\end{array}$ & Salarios & $\begin{array}{l}\text { Valor } \\
\text { agregado }\end{array}$ & $\begin{array}{l}\text { Valor de } \\
\text { prectucción }\end{array}$ \\
\hline Tijuana & 126 & 20.3 & 11057 & 9.1 & 527.7 & 701.1 & 2504.5 \\
\hline Ensenada & 5 & 0.8 & 207 & 0.2 & 9.4 & 14.5 & 37.0 \\
\hline Mexicali & 75 & 12.1 & 7519 & 6.2 & 366.8 & 523.5 & 1858.3 \\
\hline Tecate & 25 & 4.0 & 640 & 0.5 & 23.4 & 32.9 & 72.8 \\
\hline HOTEL BAJA & & & & & & & \\
\hline CALIFORNIA & 231 & 37.3 & 19.423 & 16.0 & 927.3 & 1272.0 & 4472.6 \\
\hline $\begin{array}{l}\text { BAJA CALIFORNIA } \\
\text { SUR (La Paz) }\end{array}$ & 5 & 0.8 & 176 & $\underline{0.1}$ & 7.3 & 9.3 & 32.9 \\
\hline $\begin{array}{l}\text { CHIHUAHUA } \\
\text { (Ciudad Juárez) }\end{array}$ & 124 & $\underline{20.0}$ & 38509 & 31.6 & 1706.8 & 2524.4 & 8767.2 \\
\hline San Luis Rio Colorado & 2 & 0.3 & 225 & 0.2 & 10.3 & 14.1 & 48.8 \\
\hline Nogales & 43 & 6.9 & 12878 & 10.6 & 540.3 & 703.8 & 3261.0 \\
\hline Agua Prieta & 20 & 3.2 & 4526 & 3.7 & 151.5 & 171.3 & 863.7 \\
\hline TOTAL SONORA & 65 & 10.5 & 17629 & 14.5 & 702.1 & 889.2 & 4173.5 \\
\hline Ciudad Acuña & 11 & 1.8 & 3006 & 2.5 & 100.4 & 110.1 & 382.5 \\
\hline Piedras Negras & 19 & 3.1 & 3415 & 2.8 & 130.7 & 155.8 & 598.0 \\
\hline TOTAL COAHUILA & $\underline{30}$ & $\underline{4.8}$ & $\underline{6421}$ & $\underline{5.3}$ & 231.1 & $\underline{265.9}$ & 980.5 \\
\hline Nuevo Laredo & 14 & 2.3 & 2468 & 2.0 & 103.1 & 122.2 & 300.2 \\
\hline Reynosa & 17 & 2.7 & 4996 & 4.1 & 197.9 & 285.1 & 1366.8 \\
\hline Matam oros & $51^{\circ}$ & 8.2 & 15742 & 12.9 & 492.4 & 654.3 & 2793.8 \\
\hline TOTAL TAMAULIPAS & $\underline{82}$ & $\underline{26.5}$ & $\underline{23206}$ & $\underline{19.1}$ & 793.4 & 1855.0 & 4460.8 \\
\hline TOTAL DE LA & & & & & & & \\
\hline FRONTERA & 537 & $\underline{86.6}$ & $\underline{105364}$ & $\underline{86.5}$ & $4 \underline{368.0}$ & 6022.4 & 22887.2 \\
\hline INTERIOR DE MEXICO & 83 & $\underline{13.4}$ & $\underline{16403}$ & $\underline{13.5}$ & 535.8 & 1282.4 & 2741.5 \\
\hline TOTAL NACIONAL & $\underline{620}$ & $\underline{100}$ & $\underline{121767}$ & $\underline{100}$ & 4903.8 & 73 304.8 & 25628.7 \\
\hline
\end{tabular}

FUENTE : Secretaría de Patrimonio y Fomento Industrial.Registro Nacionalde la Industria Maquiladora. 1980. 
Se puede hablar de una internacionalización parcial de la zona fronteriza mexicana, con el desarrollo de enclaves de maquiladoras (en donde después de los norteamericanos, los japoneses están presentes y los europeos enuncian su intervención) directamente ligadas al mercado y a las firmas americanas por medio de la subcontratación.

Finalmente, la zona fronteriza aparece como dotada de un nuevo potencial de desarrollo "industrial" ligado a la demanda energética norteamericana:

- El descubrimiento de importantes reservas de gas natural al sur del Río Bravo, de petróleo en Baja California y de carbón en Coahuila, sitúa a la frontera como un lugar privilegiado para la construcción de refinerías y centrales termoeléctricas pudiendo proveer el sudoeste de los Estados Unidos.

- La realización de estudios para desarrollos termoeléctricos en Baja California a base de petróleo, cuyos clientes potenciales serían las metrópolis californianas.

- En 1980, un acuerdo entre México y Estados Unidos establece la interconexión permanente de las redes eléctricas entre los dos países, previendo la exportación de excedentes mexicanos.

- Después de enero de 1980 el gasoducto que liga al Sureste mexicano con la frontera provee la red texana.

Con base en estos hechos, que constituyen una política de pequeños pasos, parece comenzar a estructurarse la cooperación deseada por el presidente Reagan con respecto a un mercado común energético entre los Estados Unidos-Canadá-México.

Es una frontera de cooperación energética de carácter estratégico lo que se perfila en este horizonte, en el que México, potencia media, permanece dependiente de los Estados Unidos. 
FIGURA 2. Industrialización de la frontera: industria maquiladora en junio de $\mathbf{1 9 8 0 .}$

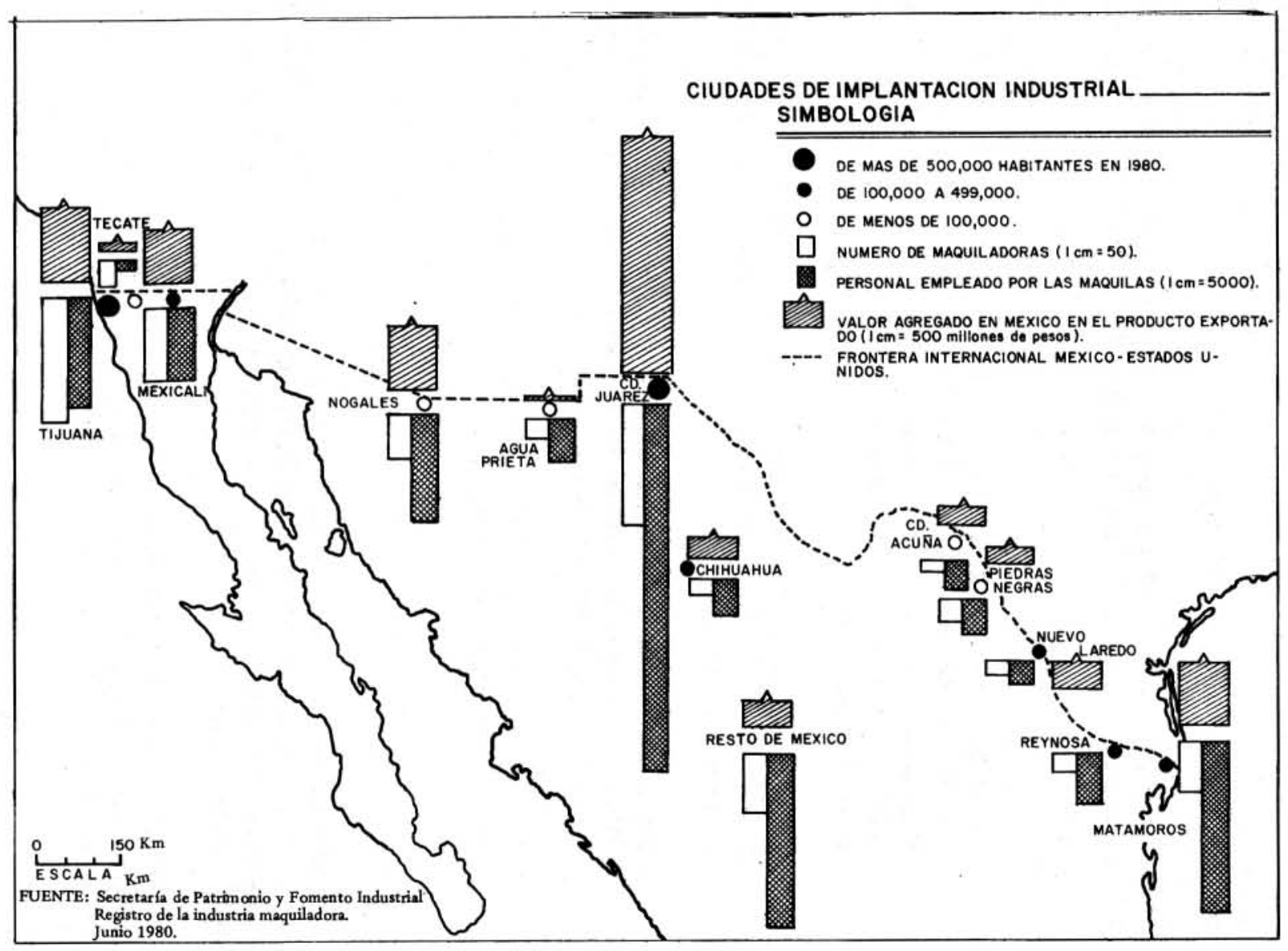




\section{BIBLIOGRAFIA}

BUSTAMANTE, Jorge, Francisco Malagamba. México-Estados Unidos. Bibliografía general sobre estudios fronterizos. El Colegio de México. 1980, 251 pp.

FORO INTERNACIONAL Vol. XVIII jan-mars 1978 No. 3, consagrado a los migrantes mexicanos y chicanos. SEPULVEDA, César. La frontera norte de México. Historia, conflictos. 1762-1975 Editorial Porrúa. 1976, $170 \mathrm{pp}$.

XIRAU ICAZA, Joaquín, Miguel Diaz. Nuestra dependencia fronteriza. Archivo del Fondo No. 48. F.C.E. 1976,170 pp.

FERNANDEZ, Raúl A. The United States-México border. A politic-economic profile. University of Notre-Dame Press. 1977. 174 pp.

ROSS, Stanley editor. Views across the border. The United States and Mexico. University of New México Press. $1978.456 \mathrm{pp}$.

REVEL-MOUROZ, Jean, Claude Bataillon. "Les migrations mexicaines vers les Etats Unis et la frontiére nord du Mexique". Revue Tiers-Monde No. 69 jan-mars $1977.55-76$ pp.

-_- "Economie frontaliére et organisation de l'espace. Réflexions á partir de la frontiére Mexique-Etats Unis". Cahiers des Amériques Latines. No. 18, 1978. 7-16 pp.

-_-_"Perméabilité de la frontiére Mexique-Etats-Unis". Bull. Assoc. Géog. Francais Nọo 470471 mai-juin 1980. 227-234 pp.

REVEL-MOUROZ, Jean, Alain Vanneph. "Enclave pétroliére et enclave frontaliére dans le Nord-Est du Mexique: Rey nosa”. Cahiers des Amériques Latines. No. 20 1979. 95-110 pp. 